(C) 2022, The Authors. Published by Elsevier Inc. and Fass Inc. on behalf of the American Dairy Science Association ${ }^{\circledR}$. This is an open access article under the CC BY license (http://creativecommons.org/licenses/by/4.0/).

\title{
Functional analysis of the second methyltransferase in the bacteriophage exclusion system of Lactobacillus casei Zhang
}

\author{
Wenyan Hui, ${ }^{1,2 *} \odot$ Wenyi Zhang, ${ }^{1,2 *} \odot$ Jing Li, ${ }^{1,2}$ Lai-Yu Kwok, ${ }^{1,2} \oplus$ Heping Zhang, ${ }^{1,2} \oplus$ Jian Kong, ${ }^{3} \dagger \odot$ \\ and Tiansong Sun ${ }^{1,2} \dagger$ \\ ${ }^{1}$ Key Laboratory of Dairy Biotechnology and Engineering, Ministry of Education, Inner Mongolia Agricultural University, Hohhot 010018 , \\ P. R. China \\ ${ }^{2}$ Key Laboratory of Dairy Products Processing, Ministry of Agriculture, Inner Mongolia Agricultural University, Hohhot 010018, P. R. China \\ ${ }^{3}$ State Key Laboratory of Microbial Technology, Shandong University, Qingdao 266237, P. R. China
}

\section{ABSTRACT}

The antiphage ability is an important feature of fermentation strains in the dairy industry. Our previous work described the bacteriophage exclusion (BREX) system in the probiotic strain, Lactobacillus casei Zhang. The function of $L$. casei Zhang $p g l X$ gene in mediating $5^{\prime}$-ACRC ${ }^{\mathrm{m} 6} \mathrm{AG}-3^{\prime}$ methylation was also confirmed. This study aimed to further dissect the function of the BREX system of $L$. casei Zhang by inactivating its second methyltransferase gene (LCAZH_2054). The methylome of the mutant, L. casei Zhang $\triangle 2054$, was profiled by single-molecule real-time sequencing. Then, the cell morphology, growth, plasmid transformation efficiency, and stability of the wildtype and mutant were compared. The mutant did not have an observable effect in microscopic and colony morphology, but it reached a higher cell density after entering the exponential phase without obvious increase in the cell viability. The mutant had fewer $5^{\prime}-\mathrm{ACRC}{ }^{\mathrm{m} 6} \mathrm{AG}-3^{\prime}$ methylation compared with the wildtype (1835 versus 1906). Interestingly, no significant difference was observed in the transformation efficiency between the 2 strains when plasmids without cognate recognition sequence (pSec:Leiss:Nuc and $\mathrm{pG}^{+}$host9) were transformed, contrasting to transforming cells with cognate recognition sequence-containing plasmids (pMSP3535 and pTRKH2). The efficiency of transforming pMSP3535 into the LCAZH_2054 mutant was significantly lower than the wildtype, whereas an opposite trend was seen in pTRKH2 transformation. Moreover, compared with

Received July 13, 2021.

Accepted October 13, 2021.

*These authors contributed equally to this work.

†Corresponding authors: kongjian@sdu.edu.cn and sts9940@sina com the wildtype, the mutant strain had higher capacity in retaining pMSP3535 and lower capacity in retaining pTRKH2, suggesting an unequal tolerance level to different foreign DNA. In conclusion, $L C A Z H \_2054$ was not directly responsible for $5^{\prime}$-ACRC ${ }^{\mathrm{m} 6} \mathrm{AG}-3^{\prime}$ methylation in $L$. casei Zhang, but it might help regulate the function and specificity of the BREX system.

Key words: Lactobacillus casei Zhang, bacteriophage exclusion system, phage infection, methyltransferase, transformation efficiency

\section{INTRODUCTION}

Bacteriophages are the most numerous organisms on Earth. They perpetuate by infecting specific bacterial or archaeal hosts (Sharma et al., 2017). Bacteriophages are generally considered harmful although they do not directly cause human diseases. Many phages carry antibiotic genes in their genomes and may facilitate the spread of antibiotic resistance genes between bacteria via horizontal gene transfer. Moreover, some of them can infect food starter cultures and decrease the efficiency of food fermentation, ultimately resulting in significant economic loss (Colavecchio et al., 2017).

In contrast, phage infection pressure has led to bacterial evolution of a variety of defense mechanisms that prevent bacterial extinction (Labrie et al., 2010). The main bacterial defense mechanisms include (1) virus receptor variation, (2) dormancy induction and programmed cell death, and (3) cell immunity (Makarova et al., 2012, 2013). Although some previous research has attempted to investigate the nature and components of these defense systems, our knowledge of their mechanisms of action remains incomplete, particularly for the newly reported Zorya and Thoeris defense systems (Doron et al., 2018). To minimize undesirable economic loss caused by phage infection, it would be desirable to select food starter strains that exhibit antiphage features. Thus, identifying the variety of such defense 
systems and gaining a thorough understanding of their molecular mechanisms would be of interest.

Epigenetic modifications such as DNA methylation allow bacteria to recognize genetic materials of self from nonself. In bacteria, DNA methyltransferases "mark" the DNA with specific methylation, and the most common prokaryotic methylation signatures are $\mathrm{m} 5 \mathrm{c}, \mathrm{m} 4 \mathrm{c}$, and m6a. Bacterial methyltransferases can be divided into 2 broad groups. Most methyltransferases are components of antiphage systems like restriction-modification systems or bacteriophage exclusion (BREX) systems, whereas orphan methyltransferases lack cognate restriction enzymes and have other cell functions (Marinus and Casadesus, 2009). The BREX system is widely distributed across prokaryotes, and it confers host resistance to phages and foreign plasmids by blocking phage absorption onto bacterial cell surface or phage replication (Goldfarb et al., 2015). Most BREX systems consist of 6 genes, including a Lon-like protease (coding gene brxL), an alkaline phosphatasedomain protein (coding gene $p g l Z$ ), an RNA-binding protein (coding gene brxA), a DNA methylase (coding gene $p g l X$ ), an ATPase-domain protein (coding gene $b r x C$ ), and a hypothetical protein (coding gene brxB; Goldfarb et al., 2015). Gene variations have been reported in some BREX systems, some of which consist of more than one methyltransferase. For example, the BREX system of Methanobrevibacter smithii has 5 truncated $p g l X$ genes locating near the full-length $p g l X$ gene (Goldfarb et al., 2015). The $p g l X$ gene is essential for proper functioning of the BREX system. Deleting the $p g l X$ gene would abolish the antiphage effect and the modification of genomic DNA, whereas the phenotype could be rescued by gene complementation (Gordeeva et al., 2019). However, the functions of the truncated methyltransferase genes are unclear.

Lactobacillus casei Zhang is a well-characterized probiotic strain that was isolated from koumiss collected in Inner Mongolia, China (Zhang et al., 2010). This strain has shown a wide range of beneficial functions (Xu et al., 2019; Hou et al., 2020). Our previous work has identified the BREX system of L. casei Zhang, verified the methyltransferase activity of the pglX protein, and identified the corresponding methylation recognition site (5'-ACRCAG-3'; Hui et al., 2019). The BREX system of L. casei is not a classical 6-gene system because it contains a second methyltransferase (LCAZH_2054), locating between the pglX and $p g l Z$ genes. This work aimed to characterize the function of $L C A Z H \_2054$ by constructing a gene deletion mutant. The phenotype was characterized by single-molecule real-time (SMRT) sequencing and multiple plasmid transformation assays.

\section{MATERIALS AND METHODS}

\section{Strains, Plasmids, and Growth Conditions}

Strains and plasmids used in this study were listed in Table 1. Lactobacillus casei Zhang was provided by the Lactic Acid Bacteria Cell Collection of the Inner Mongolia Agricultural University, China. The bacterial host strain, Escherichia coli DH5a, was used for plasmid cloning. The $L$. casei wildtype and mutant strains were propagated anaerobically in de Man, Rogosa, and Sharpe (MRS) broth at $37^{\circ} \mathrm{C}$ with or without antibiotics accordingly. Chloramphenicol $(10 \mu \mathrm{g} / \mathrm{mL})$ or erythromycin $(10 \mu \mathrm{g} / \mathrm{mL}$ erythromycin) was used for selecting the L. casei mutants. Luria-Bertani broth was used to cultivate E. coli strains aerobically at $37^{\circ} \mathrm{C}$. Chloramphenicol $(10 \mu \mathrm{g} / \mathrm{mL})$ or erythromycin $(250 \mu \mathrm{g} /$ $\mathrm{mL}$ ) was used to select for plasmid-transformed E. coli.

\section{Reagents Used for DNA Manipulations}

Genomic DNA of $L$. casei was purified by using a DNA extraction kit (Qiagen). Plasmid DNA was isolated using the E.Z.N.A Plasmid Mini Kit (Omega Bio-Tek). Primers used in this study were listed in Table 1. Phusion High-Fidelity DNA polymerase (ThermoFisher) was used in PCR for vector construction, whereas rTaq DNA polymerase (TaKaRa) was used in PCR for verification of successful cloning. Fragments of DNA were purified by using the DNA purification Gel Extraction Kit (Omega) or Cycle-Pure Kit (Omega). Restriction enzymes and T4 DNA ligase were purchased from TaKaRa Ltd.

\section{Construction of Gene Deletion Mutant}

To inactivate the $L C A Z H \_2054$ gene, a plasmid containing the homology arm of $L C A Z H_{-}$2054 was first constructed. The upstream $(\sim 1 \mathrm{~kb})$ and downstream $(\sim 1.1 \mathrm{~kb})$ sequences of $L C A Z H \_2054$ were amplified by PCR and cloned into the Xho I or Pme I and Eco53 KI or $B g l$ II restriction sites of pNZ5319 (Lambert et al., 2007), respectively, generating the vector pNZ53192054. One microgram of pNZ5319-2054 was transformed into wildtype $L$. casei Zhang cells to generate the lox66- $\mathrm{P}_{32}$-cat-lox 71 replacement mutant. The target double-crossover clones, chloramphenicol resistance and erythromycin sensitive, were selected by replica plating and verified by PCR. To excise the selection marker (the $\mathrm{P}_{32}$-cat sequence), $1 \mu \mathrm{g}$ of Cre expression vector pMSPcre (Xin et al., 2017) was transformed into the selected double-crossover clones. Cre protein expression was induced by nisin, and the cells were plated 
Table 1. Strains, plasmids, and primers used in this study; underlined portions of primer sequences indicate restriction sites ${ }^{1}$

\begin{tabular}{|c|c|c|}
\hline $\begin{array}{l}\text { Strain, plasmid, } \\
\text { and primer }\end{array}$ & Strain and plasmid description, primer sequence & $\begin{array}{l}\text { Reference, strain and plasmid source, } \\
\text { and restriction enzyme site }\end{array}$ \\
\hline \multicolumn{3}{|l|}{ Strain } \\
\hline Zhang $\Delta 2054$ & $L C A Z H \_2054$ gene mutant strain & This study \\
\hline \multicolumn{3}{|l|}{ Escherichia coli } \\
\hline DH5 $\alpha$ & Subcloning host & Novagen \\
\hline \multirow{2}{*}{\multicolumn{3}{|c|}{$\begin{array}{l}\text { ALI-Diue } \\
\text { Plasmid }\end{array}$}} \\
\hline & & \\
\hline pNZ5319 & $\begin{array}{l}\mathrm{Cm}^{\mathrm{r}} \mathrm{Em}^{\mathrm{r}} \text {; containing lox66-P32-cat-lox } 71 \text { cassette for multiple gene } \\
\text { replacement }\end{array}$ & Lambert et al., 2007 \\
\hline pNZ5319-2054 & $\begin{array}{l}\mathrm{Cm}^{\mathrm{r}} \mathrm{Em}^{\mathrm{r}} \text {; pNZ5319 derivative containing homologous regions up- } \\
\text { and downstream of } L C A Z H_{2} 2054\end{array}$ & This study \\
\hline pMSPcre & pMSP3535 derivative, expresses Cre under PnisA control & Xin et al., 2017 \\
\hline pMSP3535 & $\operatorname{Erm}^{\mathrm{r}}$ & Bryan et al., 2000 \\
\hline pTRKH2 & $\operatorname{Erm}^{\mathrm{r}}$ & O'Sullivan and Klaenhammer, 1993 \\
\hline \multicolumn{3}{|l|}{ Primer } \\
\hline 2054downF & GGGTTTGAGCTCATTCAGTTTAGGGGGTTGATTTTTT & $E \cos 3 K \mathrm{I}$ \\
\hline 2054downR & GAAGATCTGTTGAGGATCGCCCTTTT & $B g l I I$ \\
\hline
\end{tabular}

${ }^{1}$ Chloramphenicol resistance, $\mathrm{Cm}^{\mathrm{r}}$; erythromycin resistance, $\mathrm{Erm}^{\mathrm{R}}$.

on erythromycin-containing $\mathrm{MRS}$ agar. The $\mathrm{P}_{32}$-cat excision was verified by PCR, and the Cre expression vector was cured by growing the $\mathrm{P}_{32}$-cat-PCR-negative cells in the absence of erythromycin.

To transform L. casei Zhang or its derived strains, $200 \mu \mathrm{L}$ of preculture was statically incubated at $37^{\circ} \mathrm{C}$ in $5 \mathrm{~mL}$ of MRS broth containing $10 \mathrm{~g} / \mathrm{L}$ glycine and $0.75 \mathrm{M}$. When the optical density at $600 \mathrm{~nm}\left(\mathbf{O D}_{600}\right)$ reached 0.3 to 0.6 , bacterial cells were kept on ice for $30 \mathrm{~min}$ and collected by centrifugation for $10 \mathrm{~min}$ at $6,000 \times g$ at $4^{\circ} \mathrm{C}$. The cell pellets were then washed twice by ice-cold wash solution (1 $M$ sucrose, $3.5 \mathrm{mM}$ $\mathrm{MgCl}_{2}$ ) and resuspended in $40 \mu \mathrm{L}$ of wash solution. One microgram of plasmid was mixed with the competent cells and kept on ice for $10 \mathrm{~min}$, followed by electroporation with a BioRad Genepulser (BioRad, $2,000 \mathrm{~V}, 25 \mu \mathrm{F}, 400 \Omega$ ). Then, $1 \mathrm{~mL}$ of SMRS (MRS with $0.1 \mathrm{M} \mathrm{MgCl}_{2}$ and $0.5 \mathrm{M}$ sucrose) was added to the cuvette, and the electroporated cells were recovered at $37^{\circ} \mathrm{C}$ for $2 \mathrm{~h}$ before plating on chloramphenicol- or erythromycin-containing MRS.

\section{Analysis of Methylome by SMRT Sequencing Technology}

The total genomic DNA of the mutant strain, $L$. casei Zhang $\Delta 2054$, was extracted. SMRTbell libraries were prepared as described previously (Hui et al., 2019). Sequencing was performed on a PacBio RS II platform using standard protocols for short and long insert libraries. The bacterial methylome was analyzed by the PacBio SMRT Portal analysis platform. The RS_Modification_and_Motif_Analysis.1.4 protocol was selected to identify the positions and motifs of methylation in the genome.

\section{Cell and Colony Morphology}

Pure cultures of the wildtype and mutant strains isolated from MRS plates were picked based on colony morphology, and the cell morphology of the wildtype and mutant strains was observed after staining with the Gram stain.

\section{Bacterial Growth}

The wildtype and mutant strains were cultivated in MRS broth. Bacterial growth curves were constructed by recording the optical density $(600 \mathrm{~nm}), \mathrm{pH}$, and viable counts at 2 -h intervals over a 24 -h period. All analyses were performed in triplicate.

\section{Plasmid Transformation Efficiency}

To compare the plasmid transformation efficiency between strains, competent cells were prepared when the $\mathrm{OD}_{600}$ of the bacteria reached 0.3 . Then, $1 \mu \mathrm{g}$ of pMSP3535 (Bryan et al., 2000), pTRKH2 (O'Sullivan and Klaenhammer, 1993), pSec:Leiss:Nuc (Ribeiro et al., 2002), or $\mathrm{pG}^{+}$host9 (Biswas et al., 1993) was electroporated into the competent cells. After cell recovery in culture medium without antibiotics, cells were 
spread on erythromycin-containing MRS agar. The transformation efficiency was expressed as the number of transformants per microgram of DNA. All analyses were performed in triplicate.

\section{Plasmid Stability}

The stability of the plasmids (pMSP3535 and pTRKH2) was monitored after being transformed into the wildtype and mutant strains. Plasmid-transformed cells were subcultured in MRS broth with or without erythromycin every $12 \mathrm{~h}$ for $96 \mathrm{~h}$. After the parallel passage, cells were plated on MRS agar with or without erythromycin, respectively. The plasmid stability was calculated as the percentage of the number of colonyforming units observed after passage in erythromycincontaining MRS broth divided by the number of colonyforming units grown in MRS broth without antibiotics (Mosrati et al., 1993). All analyses were performed in triplicate.

\section{Statistical Analysis}

All data were expressed in mean \pm standard deviation. Significant difference between groups was evaluated by Student's $t$-test at the confidence level of 0.05 .

\section{RESULTS}

\section{Construction of L. casei Zhang $\Delta 2054$}

Our previous work analyzed the $p g l X$ gene in the BREX system in L. casei. This study inactivated the second methyltransferase-coding gene of the BREX system, LCAZH_2054. The upstream 1,013-bp and downstream 1,095-bp fragments of the $L C A Z H \_2054$ were amplified from the genomic DNA of the wildtype strain. The fragments were gel purified and cloned into the plasmid pNZ5319, which contained the Crelox homologous recombination cassette. The resultant pNZ5319-2054 plasmid was transformed into the wildtype cells and the $L C A Z H \_2054$ gene was replaced by a DNA fragment containing the lox sites and the chloramphenicol antibiotic resistance biomarker gene after homologous recombination. Then, the Cre expression plasmid was electroporated into the chloramphenicolresistant transformants to express the Cre enzyme, mediate the lox site recombination, and excise the chloramphenicol resistance gene. The mutant strain L. casei Zhang $\Delta 2054$ (Figure 1) was then ready for further experiments after the Cre expression plasmid was cured by continuous subculturing in MRS broth without antibiotic.

\section{Methylome Analysis of L. casei Zhang $\mathbf{\Delta 2 0 5 4}$}

The methylation of the genomic DNA of L. casei Zhang $\Delta 2054$ was analyzed by using the PacBio SMRT sequencing technology. A total of 158,738 reads were obtained, and the mean read length was $10,228 \mathrm{bp}$. The average reference coverage was up to 408.17 -fold. The sequencing quality met the data analysis requirements. The genomic sequencing analysis revealed 6-methyladenine $\left(5^{\prime}-\mathrm{ACRC}^{\mathrm{m} 6} \mathrm{AG}-3^{\prime}\right)$ in both the wildtype and the mutant strains. However, a lower level of methylation was observed in the mutant strain (1835 versus 1906 in the wildtype strain; Figure 2). Therefore, $L C A Z H \_2054$ might have partial influence on genome methylation.

\section{Biological Characteristics of Wildtype and Mutant Strains}

The microscopic appearance, colony morphology, and the bacterial growth of the wildtype and mutant were compared. The Gram-stained cells of both strains were similar, which were arranged in short rods, pairs, or chains (Figure 3a, 3b). The colony morphology of both strains was also highly similar, appearing as milky white opaque colonies with smooth surface (Figure 3c, 3d).

The wildtype and mutant strains exhibited similar pattern of growth, as shown by the growth curves plotted based on cell density $\left(\mathrm{OD}_{600}\right.$; Figure $\left.4 \mathrm{a}\right)$, acidity of culture medium (Figure 4b), and viable count (Figure $4 \mathrm{c}$ ). However, the $\mathrm{OD}_{600}$ of the mutant strain was

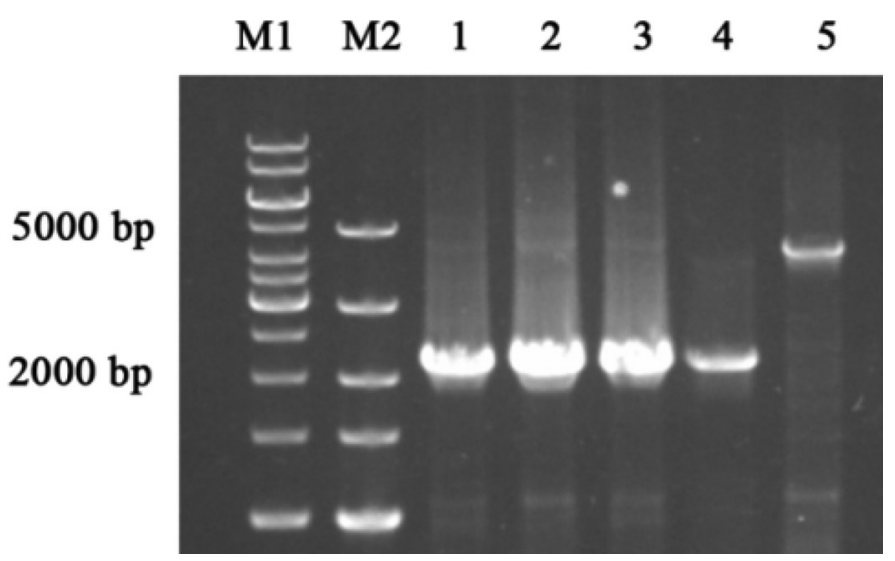

Figure 1. The PCR validation of Lactobacillus casei Zhang $\triangle 2054$, using primers 2054upF and 2054downR. The expected PCR fragment from the mutant type is about $\sim 2.1 \mathrm{~kb}$ (lanes 1-3), indicating the length of upstream and downstream homology arms, whereas the unexpected band from the wild type is $\sim 4.3 \mathrm{~kb}$ (lane 5 ), indicating the length of homology arms and the $L C A Z H_{2} 2054$ gene. Lane M1: $1 \mathrm{~kb}$ marker; lane M2: DL 5000 marker. 


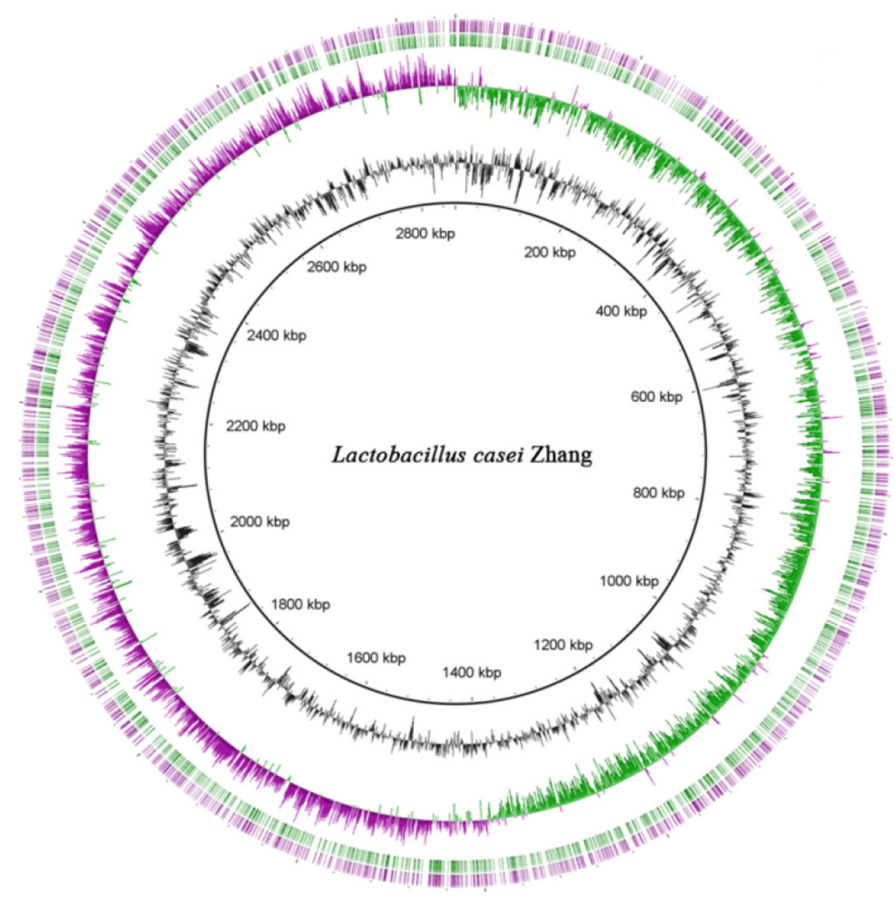

Figure 2. Comparison of $5^{\prime}$-ACRCAG-3' methylation sites of Lactobacillus casei Zhang $\Delta 2054$ and L. casei Zhang. From outside to inside, the first circle is methylation site of $L$. casei Zhang $\Delta 2054$ (in purple), and the second circle is methylation site of L. casei Zhang (in green).

consistently higher than that of the wildtype after the bacterial growth entered the exponential phase (Figure 4a). In contrast, the wildtype strain showed a consistently higher viable count compared with the mutant strain after the bacterial growth entered the stationary phase (Figure 4c).

\section{Plasmid Transformation Efficiency of Wildtype and Mutant Strains}

As part of the BREX system, the $L C A Z H \_2054$ gene might be involved in blocking the uptake of foreign DNA. So, the plasmid transformation efficiency of the wildtype and mutant strains were tested. Four plasmids, namely pMSP3535, pTRKH2, pSec:Leiss:Nuc, and $\mathrm{pG}^{+}$Host9, were included in the assays (Figure 5). The 2 strains exhibited different plasmid transformation performance, and the efficiency of transformation also varied between plasmids. The transformation efficiency of pMSP3535 in the mutant strain was significantly lower than the wildtype strain $(P<0.001)$, and such trend was reversed for pTRKH2 $(P<0.01)$. For pSec:Leiss:Nuc and $\mathrm{pG}^{+}$Host9, no significant difference was observed in the transformation efficiency between the 2 strains.

\section{Plasmid Stability in the Wildtype and Mutant Strains}

The function of the BREX system is to recognize self from nonself genetic material by degrading foreign DNA. Thus, the stability of 2 plasmids (pMSP3535 and pTRKH2) was monitored along a 96-h period after the transformation (Figure 6). The number of plasmid-containing cells continuously decreased with time for both plasmids. However, the rate of plasmid loss was higher for pMSP3535 compared with pTRKH2. On the other hand, pTRKH2 was more stable in the wildtype compared with the mutant cells beyond $24 \mathrm{~h}$ of transformation, and the difference in stability was maximum at 96 h. Such differences were not observed for pMSP3535.

\section{DISCUSSION}

Lactobacillus casei is an important member of lactic acid bacteria. It has the ability to adapt to a wide variety of environments (Wu et al., 2009; Bao et al., 2016) and is thus widely distributed across numerous ecological niches, such as yogurt, cheese, and the digestive tract of humans and animals. Lactobacillus casei is often used as a starter culture or an additive in the food industry (Dantas et al., 2016). Phage infection of lactobacilli is one problem for the food industry, as this will cause the failure of fermentation and significant economic loss (Samson and Moineau, 2013). Moreover, phage infection is one mechanism that renders genetic elements mobile, which not only worsens the problem a

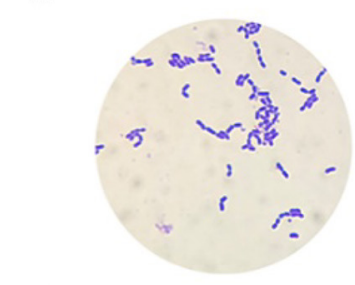

c

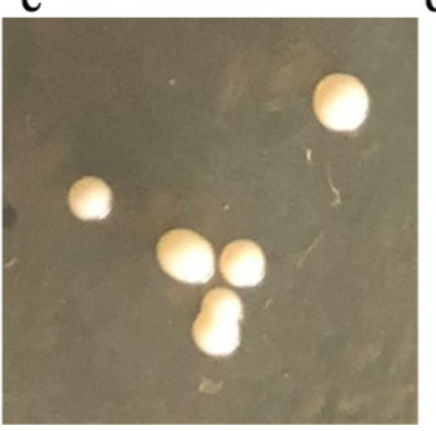

d

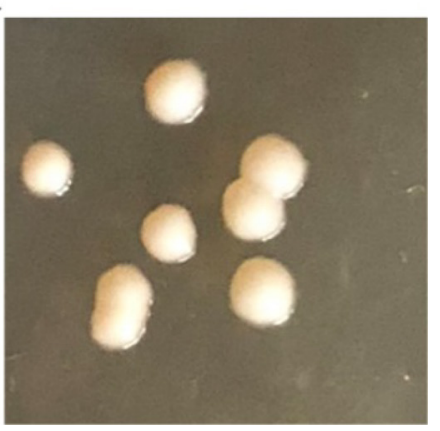

Figure 3. Gram stain appearance and colony morphology of Lactobacillus casei Zhang wildtype (a, c) and mutant $\Delta 2054$ (b, d). 
a

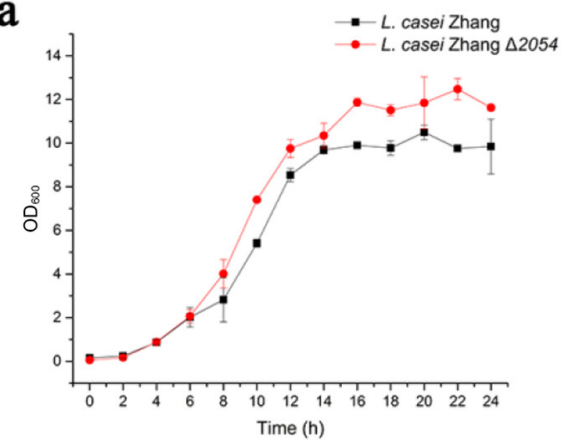

b

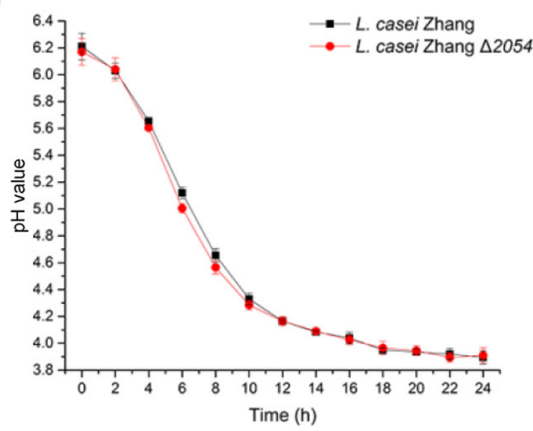

c

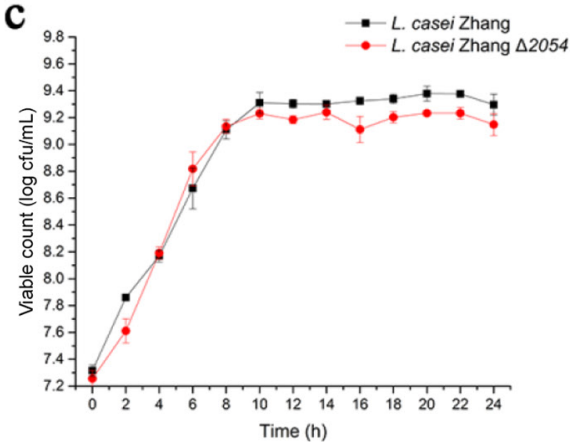

Figure 4. Growth curves of wildtype Lactobacillus casei Zhang and mutant $\Delta 2054$ constructed based on optical density at $600 \mathrm{~nm}\left(\mathrm{OD}_{600}\right.$; a), $\mathrm{pH}(\mathrm{b})$, and viable count (c). Error bars represent SD.

of spreading of antibiotic resistance genes but also leads to the acquisition of these genes by lactobacilli. The BREX system is a bacterial antiphage mechanism that helps resist the invasion of foreign DNA, and it plays an important role in protecting the cells. The probiotic strain, L. casei Zhang, was previously found to contain an atypical BREX system that has 2 genes coding for 2 putative methyltransferases. One of these was the $p \lg X$ gene that was previously characterized to exhibit functional methyltransferase activity (Hui et al., 2019). a

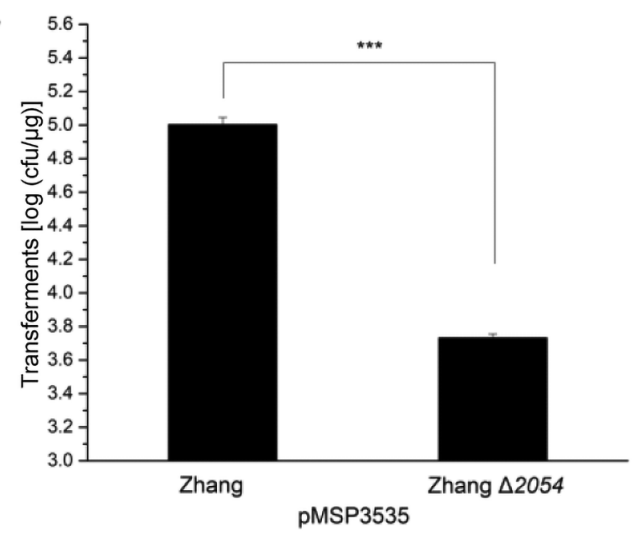

C

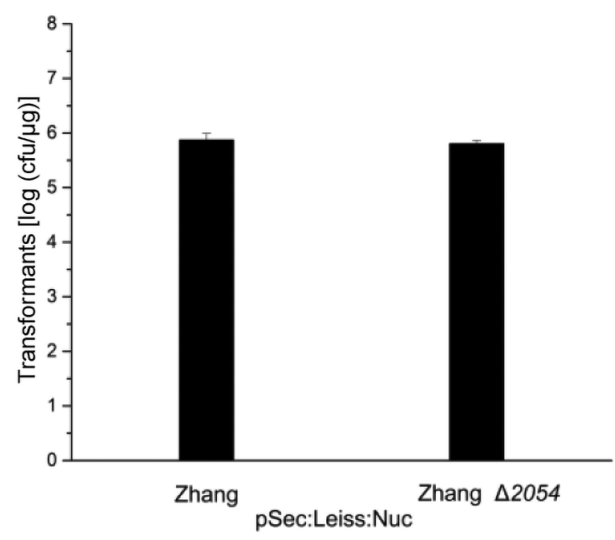

b

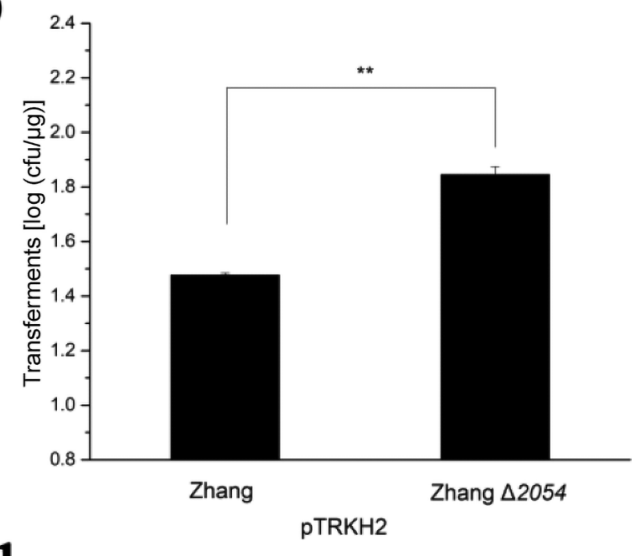

d

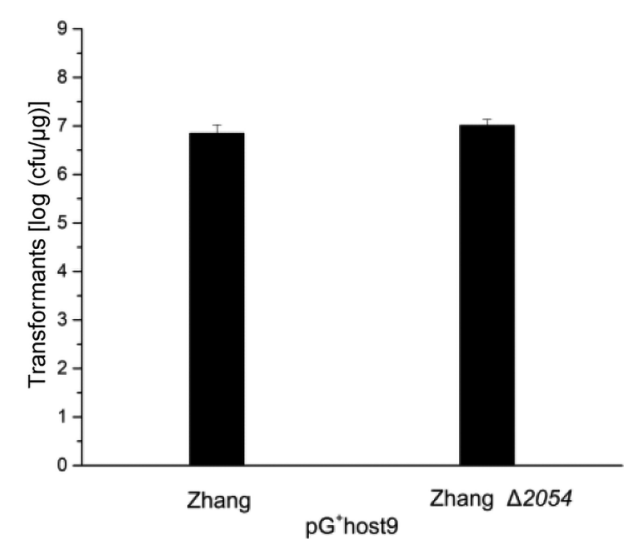

Figure 5. Plasmid transformation efficiency of wildtype Lactobacillus casei Zhang and mutant $\Delta 2054$. Difference in plasmid transformation efficiency was evaluated with Student's unpaired 2-tailed $t$-test. ${ }^{*}, * * *$ Double and triple asterisks represent a significant difference of $P<0.01$ and $P<0.001$, respectively. Error bars represent SD. 
This study further analyzed the function of the second methyltransferase-coding gene $\left(L C A Z H \_2054\right)$ in the BREX system.

This study first constructed the L. casei Zhang $\Delta 2054$ mutant, followed by profiling the methylome of the mutant by SMRT sequencing and performing plasmid transformation assays. Both the wildtype and mutant strains exhibited the same type of m6A methylation, $5^{\prime}$-ACRC ${ }^{\mathrm{m} 6} \mathrm{AG}-3^{\prime}$, utilizing the same methylation recognition sequence and bases (Zhang et al., 2015). However, one mild difference between the 2 strains was the decrease in the number of methylation detected in the genome of the mutant strain (1907 versus 1846 in the wildtype). Ouellette et al. (2015) disrupted the methyltransferase gene, HVO_A0006, of Haloferax volcanii H26. The resultant mutant not only showed a reduced level of m6A methylation but also exhibited changes in its methylation recognition sequence. Thus, the study concluded that HVO_A0006 was associated with m6A methylation in $H$. volcanii $\mathrm{H} 26$. The current study was only found a slight decrease in m6A methylation in the L. casei Zhang $\Delta 2054$ mutant contrasting to abrogation of $95.65 \%$ of methylation in the case of deleting the other methyltransferase gene $(p g l X)$ in $L$. casei Zhang in our previous work (Hui et al., 2019), suggesting that the m6A methylation in $L$. casei Zhang was mainly responsible for the action of the $p g l X$ gene and $L C A Z H \_2054$ may have played a less direct role in such a process. The mild difference could even represent some level of technical variation in SMRT sequencing.

Generally, DNA methyltransferases in bacteria play important roles in regulating basic cellular biological processes (Vasu and Nagaraja, 2013). Methyltransferases not only participate in the antiphage activity, but some can also act as cell cycle regulators to control basic processes such as chromosome replication, transcription, and repair (Reisenauer et al., 1999). In

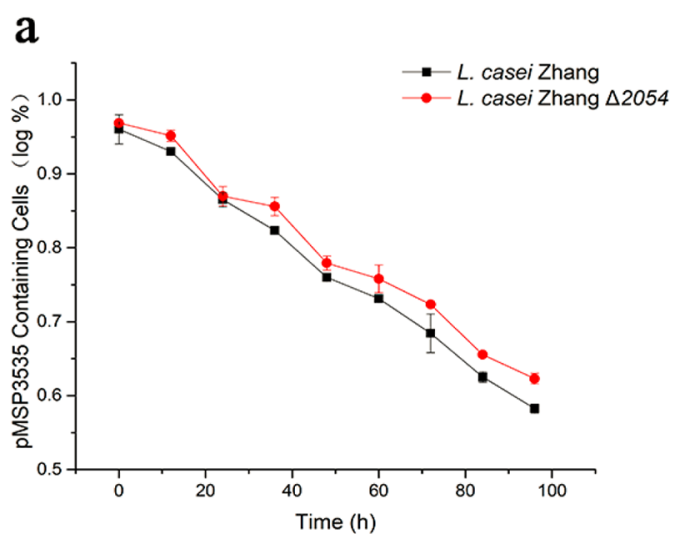

Caulobacter crescentus and other $\alpha$-proteobacteria bacteria, such as Rhizobium meliloti, Agrobacterium tumefaciens, and Brucella abortus, DNA methylation could regulate cell cycle and chromosomal DNA replication (Marczynski, 1999; Collier et al., 2007; Mohapatra et al., 2014). Mutant strains of Salmonella typhimurium lacking adenine methyltransferases showed weakened growth, which proved the role of methyltransferase in cell growth regulation (Aloui et al., 2011). However, abrogating DNA methylation in Helicobacter pylori did not affect cell and DNA replication, as the bacterial growth was not altered under normal culture conditions (Kumar et al., 2018). Herein, inactivating the $L C A Z H \_2054$ gene did not severely affect the growth of the mutant strain. Yet, it is interesting to note that, in comparison with the wildtype strain, the mutant strain reached a higher cell density after entering the exponential phase without obvious increase in cell viability. The cellular mechanism behind the changes in bacterial growth behavior and the exact molecular role of the $L C A Z H \_2054$ gene in the mutant cells remain to be further elucidated.

Plasmid transformation efficiency and plasmid stability are 2 important indices for assessing the function of methyltransferases (Vasu and Nagaraja, 2013). This study found that the efficiency of transforming pMSP3535 into the LCAZH_2054 mutant strain was significantly lower than the wildtype strain, whereas an opposite trend was seen in the transformation efficiency of pTRKH2. However, no difference was observed in the plasmid transformation efficiency for another 2 tested plasmids, pSec:Leiss:Nuc and $\mathrm{pG}^{+}$host9. The divergent response between the 2 groups of plasmids was likely due to the presence of methylation recognition sequence $5^{\prime}$-ACRCAG-3', which was found in pMSP3535 and pTRKH2 but not pSec:Leiss:Nuc and $\mathrm{pG}^{+}$host9. Yet, it is unclear why transforming pMSP3535 and pTRKH2

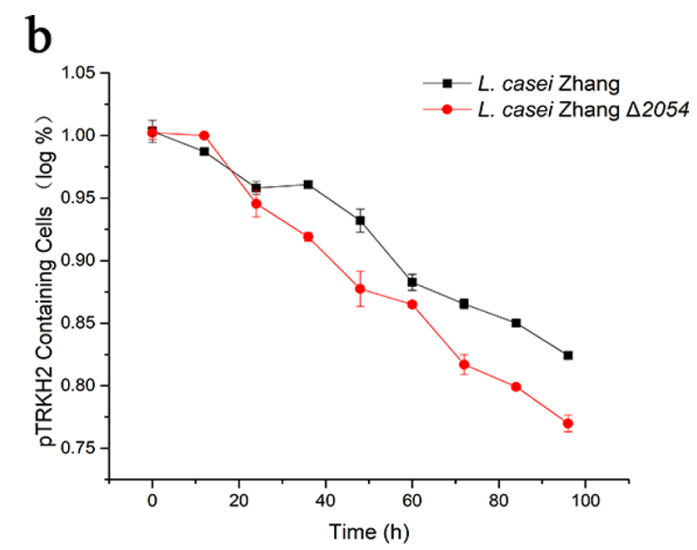

Figure 6. Plasmid stability after transformation of (a) pMSP3535 and (b) pTRKH2 into wildtype Lactobacillus casei Zhang and mutant $\Delta 2054$ cells. Error bars represent SD. 
into the mutant cells yielded opposite responses. Similarly, the stability of pMSP3535 and pTRKH2 also varied after being transformed into the mutant cells. These results suggested that $L C A Z H \_2054$ might be involved in regulating the specificity of the function of the BREX system. We speculate that cryptic unidentified sequences might be encoded in these 2 plasmids to regulate downstream responses. The mechanism of functional regulation of the BREX system merits further elucidation.

\section{CONCLUSIONS}

By using a combination of gene inactivation technique, SMRT sequencing, and multiple plasmid transformation assays, this work preliminarily explored the function of $L C A Z H_{-} 2054$ in the BREX system of $L$. casei Zhang. Our data suggested that $L C A Z H \_2054$ was not directly responsible for $5^{\prime}-\mathrm{ACRC}^{\mathrm{m} 6} \mathrm{AG}-3^{\prime}$ methylation in $L$. casei Zhang, but it might help regulate the function and specificity of the BREX system. The exact role of this gene in regulating the BREX system requires further investigation.

\section{ACKNOWLEDGMENTS}

This research was supported by the National Natural Science Foundation of China (Hohhot; grant no. 31922071) and the Natural Science Foundation of the Inner Mongolia Autonomous Region of China (Hohhot; 2021ZD08). The authors have not stated any conflicts of interest.

\section{REFERENCES}

Aloui, A., J. Tagourti, A. El May, D. Joseleau Petit, and A. Landoulsi. 2011. The effect of methylation on some biological parameters in Salmonella enterica serovar Typhimurium. Pathol. Biol. (Paris) 59:192-198. https://doi.org/10.1016/j.patbio.2009.03.011.

Bao, Q., Y. Song, H. Xu, J. Yu, W. Zhang, B. Menghe, H. Zhang, and Z. Sun. 2016. Multilocus sequence typing of Lactobacillus casei isolates from naturally fermented foods in China and Mongolia. J. Dairy Sci. 99:5202-5213. https://doi.org/10.3168/jds.2016-10857.

Biswas, I., A. Gruss, S. D. Ehrlich, and E. Maguin. 1993. High-efficiency gene inactivation and replacement system for gram-positive bacteria. J. Bacteriol. 175:3628-3635. https://doi.org/10.1128/jb .175.11.3628-3635.1993.

Bryan, E. M., T. Bae, M. Kleerebezem, and G. M. Dunny. 2000. Improved vectors for nisin-controlled expression in gram-positive bacteria. Plasmid 44:183-190. https://doi.org/10.1006/plas.2000 .1484 .

Colavecchio, A., B. Cadieux, A. Lo, and L. D. Goodridge. 2017. Bacteriophages contribute to the spread of antibiotic resistance genes among foodborne pathogens of the Enterobacteriaceae family - A review. Front. Microbiol. 8:1108. https://doi.org/10.3389/fmicb 2017.01108.

Collier, J., H. H. McAdams, and L. Shapiro. 2007. A DNA methylation ratchet governs progression through a bacterial cell cycle. Proc. Natl. Acad. Sci. USA 104:17111-17116. https://doi.org/10.1073/ pnas.0708112104.
Dantas, A. B., V. F. Jesus, R. Silva, C. N. Almada, E. A. Esmerino, L. P. Cappato, M. C. Silva, R. S. Raices, R. N. Cavalcanti, C. C. Carvalho, A. S. Sant'Ana, H. M. Bolini, M. Q. Freitas, and A. G. Cruz. 2016. Manufacture of probiotic Minas Frescal cheese with Lactobacillus casei Zhang. J. Dairy Sci. 99:18-30. https://doi.org/ 10.3168/jds.2015-9880.

Doron, S., S. Melamed, G. Ofir, A. Leavitt, A. Lopatina, M. Keren, G. Amitai, and R. Sorek. 2018. Systematic discovery of antiphage defense systems in the microbial pangenome. Science 359:eaar4120. https://doi.org/10.1126/science.aar4120.

Goldfarb, T., H. Sberro, E. Weinstock, O. Cohen, S. Doron, Y. Charpak-Amikam, S. Afik, G. Ofir, and R. Sorek. 2015. BREX is a novel phage resistance system widespread in microbial genomes. EMBO J. 34:169-183. https://doi.org/10.15252/embj.201489455.

Gordeeva, J., N. Morozova, N. Sierro, A. Isaev, T. Sinkunas, K. Tsvetkova, M. Matlashov, L. Truncaite, R. D. Morgan, N. V. Ivanov, V. Siksnys, L. Zeng, and K. Severinov. 2019. BREX system of Escherichia coli distinguishes self from non-self by methylation of a specific DNA site. Nucleic Acids Res. 47:253-265. https://doi.org/ 10.1093/nar/gky1125.

Hou, Q., F. Zhao, W. Liu, R. Lv, W. W. T. Khine, J. Han, Z. Sun, Y. K. Lee, and H. Zhang. 2020. Probiotic-directed modulation of gut microbiota is basal microbiome dependent. Gut Microbes 12:1736974. https://doi.org/10.1080/19490976.2020.1736974.

Hui, W., W. Zhang, L. Y. Kwok, H. Zhang, J. Kong, and T. Sun. 2019. A novel bacteriophage exclusion (BREX) system encoded by the pglX gene in Lactobacillus casei Zhang. Appl. Environ. Microbiol. 85. https://doi.org/10.1128/AEM.01001-19.

Kumar, S., B. C. Karmakar, D. Nagarajan, A. K. Mukhopadhyay, R. D. Morgan, and D. N. Rao. 2018. N4-cytosine DNA methylation regulates transcription and pathogenesis in Helicobacter pylori. Nucleic Acids Res. 46:3429-3445. https://doi.org/10.1093/ nar/gky126.

Labrie, S. J., J. E. Samson, and S. Moineau. 2010. Bacteriophage resistance mechanisms. Nat. Rev. Microbiol. 8:317-327. https://doi .org/10.1038/nrmicro2315.

Lambert, J. M., R. S. Bongers, and M. Kleerebezem. 2007. Cre-loxbased system for multiple gene deletions and selectable-marker removal in Lactobacillus plantarum. Appl. Environ. Microbiol. 73:1126-1135. https://doi.org/10.1128/AEM.01473-06.

Makarova, K. S., V. Anantharaman, L. Aravind, and E. V. Koonin. 2012. Live virus-free or die: Coupling of antivirus immunity and programmed suicide or dormancy in prokaryotes. Biol. Direct 7:40. https://doi.org/10.1186/1745-6150-7-40.

Makarova, K. S., Y. I. Wolf, and E. V. Koonin. 2013. Comparative genomics of defense systems in archaea and bacteria. Nucleic Acids Res. 41:4360-4377. https://doi.org/10.1093/nar/gkt157.

Marczynski, G. T. 1999. Chromosome methylation and measurement of faithful, once and only once per cell cycle chromosome replication in Caulobacter crescentus. J. Bacteriol. 181:1984-1993. https: //doi.org/10.1128/JB.181.7.1984-1993.1999.

Marinus, M. G., and J. Casadesus. 2009. Roles of DNA adenine methylation in host-pathogen interactions: Mismatch repair, transcriptional regulation, and more. FEMS Microbiol. Rev. 33:488-503. https://doi.org/10.1111/j.1574-6976.2008.00159.x.

Mohapatra, S. S., A. Fioravanti, and E. G. Biondi. 2014. DNA methylation in Caulobacter and other Alphaproteobacteria during cell cycle progression. Trends Microbiol. 22:528-535. https://doi.org/ 10.1016/j.tim.2014.05.003

Mosrati, R., N. Nancib, and J. Boudrant. 1993. Variation and modeling of the probability of plasmid loss as a function of growth rate of plasmid-bearing cells of Escherichia coli during continuous cultures. Biotechnol. Bioeng. 41:395-404. https://doi.org/10.1002/ bit.260410402

O'Sullivan, D. J., and T. R. Klaenhammer. 1993. High- and low-copy-number Lactococcus shuttle cloning vectors with features for clone screening. Gene 137:227-231. https://doi.org/10.1016/0378 $-1119(93) 90011-Q$.

Ouellette, M., L. Jackson, S. Chimileski, and R. T. Papke. 2015. Genome-wide DNA methylation analysis of Haloferax volcanii $\mathrm{H} 26$ and identification of DNA methyltransferase related PD-(D/E) 
XK nuclease family protein HVO_A0006. Front. Microbiol. 6:251. https://doi.org/10.3389/fmicb.2015.00251.

Reisenauer, A., L. S. Kahng, S. McCollum, and L. Shapiro. 1999. Bacterial DNA methylation: A cell cycle regulator? J. Bacteriol. 181:5135-5139. https://doi.org/10.1128/JB.181.17.5135-5139 .1999 .

Ribeiro, L. A., V. Azevedo, Y. Le Loir, S. C. Oliveira, Y. Dieye, J. C. Piard, A. Gruss, and P. Langella. 2002. Production and targeting of the Brucella abortus antigen L7/L12 in Lactococcus lactis: A first step towards food-grade live vaccines against brucellosis. Appl. Environ. Microbiol. 68:910-916. https://doi.org/10.1128/ AEM.68.2.910-916.2002.

Samson, J. E., and S. Moineau. 2013. Bacteriophages in food fermentations: New frontiers in a continuous arms race. Annu. Rev. Food Sci. Technol. 4:347-368. https://doi.org/10.1146/annurev-food -030212-182541.

Sharma, S., S. Chatterjee, S. Datta, R. Prasad, D. Dubey, R. K. Prasad, and M. G. Vairale. 2017. Bacteriophages and its applications: An overview. Folia Microbiol. (Praha) 62:17-55. https://doi .org/10.1007/s12223-016-0471-x.

Vasu, K., and V. Nagaraja. 2013. Diverse functions of restriction-modification systems in addition to cellular defense. Microbiol. Mol. Biol. Rev. 77:53-72. https://doi.org/10.1128/MMBR.00044-12.

Wu, R., L. Wang, J. Wang, H. Li, B. Menghe, J. Wu, M. Guo, and H. Zhang. 2009. Isolation and preliminary probiotic selection of lactobacilli from koumiss in Inner Mongolia. J. Basic Microbiol. 49:318-326. https://doi.org/10.1002/jobm.200800047.

Xin, Y., T. Guo, Y. Mu, and J. Kong. 2017. Identification and functional analysis of potential prophage-derived recombinases for ge- nome editing in Lactobacillus casei. FEMS Microbiol. Lett. 364. https://doi.org/10.1093/femsle/fnx243.

Xu, H., F. Zhao, Q. Hou, W. Huang, Y. Liu, H. Zhang, and Z. Sun. 2019. Metagenomic analysis revealed beneficial effects of probiotics in improving the composition and function of the gut microbiota in dogs with diarrhoea. Food Funct. 10:2618-2629. https://doi.org/ 10.1039/C9FO00087A.

Zhang, W., Z. Sun, B. Menghe, and H. Zhang. 2015. Short communication: Single molecule, real-time sequencing technology revealed species- and strain-specific methylation patterns of 2 Lactobacillus strains. J. Dairy Sci. 98:3020-3024. https://doi.org/10.3168/ jds.2014-9272.

Zhang, W., D. Yu, Z. Sun, R. Wu, X. Chen, W. Chen, H. Meng, S. $\mathrm{Hu}$, and H. Zhang. 2010. Complete genome sequence of Lactobacillus casei Zhang, a new probiotic strain isolated from traditional homemade koumiss in Inner Mongolia, China. J. Bacteriol. 192:5268-5269. https://doi.org/10.1128/JB.00802-10.

\section{ORCIDS}

Wenyan Hui $\odot$ https://orcid.org/0000-0003-0992-7833

Wenyi Zhang ๑ https://orcid.org/0000-0001-5530-4210

Lai-Yu Kwok ๑ https://orcid.org/0000-0001-8791-1269

Heping Zhang (1) https://orcid.org/0000-0001-6632-2641

Jian Kong ๑ https://orcid.org/0000-0002-2872-2078 